\title{
NURSES' ASSESSMENT OF THE MANDATORY CONTINUING PROFESSIONAL DEVELOPMENT PROGRAM IN OSUN STATE, SOUTHWEST, NIGERIA
}

\author{
Adebukunola Olajumoke Afolabi ${ }^{1}$, Phebe Olufunke Abioye ${ }^{2}$, \\ Mary Olufunke Akin-Ayankunle ${ }^{3}$, Monisola Yetunde Jane Omishakin ${ }^{4}$, \\ Adeola Omobola Adegoke ${ }^{5}$, Adebayo Lukman Ademola ${ }^{6}$, \\ Margaret Omobonike Ogundeji ${ }^{7}$, Samuel Olumide Faniran ${ }^{8}$ \\ and Tolulope Margaret Agboire ${ }^{9}$
}

${ }^{1}$ Clinical Nursing Services, Obafemi Awolowo University Teaching Hospitals Complex, IleIfe, Osun state, Nigeria. Email: bukieafolabi@yahoo.com; ORCID ID: 0000-0002-3332-0524

${ }^{2}$ Ministry of Health, Osun state, Nigeria. Email: oluabifunke@yahoo.com

${ }^{3}$ Osun State School of Nursing, Osogbo, Nigeria. Email: maryolufunke46@ gmail.com

${ }^{4}$ Department of Nursing Science, Redeemer's University, Ede, Osun state, Nigeria.

Email: omishakinm@ run.edu.ng; ORCID ID: 0000-0002-0601-509X

${ }^{5}$ Osun State University Teaching Hospital, Osogbo, Nigeria. Email:ayonderexcel@ gmail.com ${ }^{6}$ Primary Health Care Board, Osogbo, Osun State, Nigeria. Email: bayoademola3731@ gmail.com ${ }^{7}$ School of Nursing, Obafemi Awolowo University Teaching Hospitals Complex, Wesley

Guild Hospital, Ilesa, Osun state, Nigeria. Email: ogundejinike@gmail.com

${ }^{8}$ Osun State University Teaching Hospital, Osogbo, Nigeria. Email: olusuenmide@ gmail.com

${ }^{9}$ State specialist Hospital, Osogbo, Osun state, Nigeria. Email: tolumaggi@gmail.com

Cite this article:

Afolabi A.O., Abioye P.O., Akin-Ayankunle M.O., Omishakin M.Y.J., Adegoke A.O., Ademola A.L., Ogundeji M.O., Faniran S.O., Agboire T.M. (2021), Nurses' Assessment of the Mandatory Continuing Professional Development Program in Osun State, Southwest, Nigeria. African Journal of Health, Nursing and Midwifery 4(6), 119-138. DOI: 10.52589/AJHNM5VES8SQN.

\section{Manuscript History}

Received: 17 Nov 2021

Accepted: 10 Dec 2021

Published: 30 Dec 2021

Copyright $\odot 2020$ The Author(s). This is an Open Access article distributed under the terms of Creative Commons Attribution-NonCommercialNoDerivatives 4.0 International (CC BY-NC-ND 4.0), which permits anyone to share, use, reproduce and redistribute in any medium, provided the original author and source are credited.

119
ABSTRACT: Continuing Professional Development Programs have been identified as an important strategy towards improving basic professional skills and competence of health care professionals. This study explored nurses' perception about the Mandatory Continuing Professional Development Program (MCPDP) and assessed nurses' satisfaction with the Continuing Professional Development Program in Nigeria. Study adopted sequential explanatory mixed methods, using both quantitative and qualitative data collection methods. The quantitative aspect included 412 nurses in Osun state, Nigeria selected through multistage sampling. Data was analyzed at univariate, bivariate and multivariate levels using appropriate statistics, level of significance was $p<0.05$. The qualitative aspect of the study employed in-depth interview; responses were analyzed thematically. Findings showed that $72.8 \%$ of the nurses had positive perception about the MCPDP, $66.3 \%$ assessed the MCPDP training as very useful, $31.3 \%$ and $2.4 \%$ assessed the training as moderately useful and useful respectively, $57.0 \%$ were very satisfied with the MCPDP training, $41.5 \%$ were satisfied while1.5\% nurses were indifferent. Regression analysis revealed that nurses' years of working experience $(O R=0.24$, $C I=0.10-0.62, p=0.003)$ significantly influenced perception about the MCPDP. Study concluded that professionalism in nursing should focus on ensuring quality years of working experience and effective Continuous Professional Development for all categories of nurses.

KEYWORDS: Nurses; Mandatory Continuous Professional Development Program; Nigeria 


\section{INTRODUCTION}

Mandatory Continuing Professional Development Program (MCPDP) is a strategic learning activity based on educational and experiential training towards improvement in knowledge, proficiency and competence of professionals (Lucy, Johnson \& Long, 2012). Banning \& Stafford (2008) similarly considers MCPDP as a lifelong learning process for all persons or groups that is directed towards meeting the needs of individuals and to provide quality healthcare.

Globally, healthcare domains are continuously progressing and improving through advancement in knowledge and skills which are essential for evidence-based practice and excellence in health care delivery (Banova, 2014). In addition, MCPDP structures and programs have evolved from being a single professional educational design and formal instructive method of training to educational models that are creative, vibrant, and learner's focused (Lawrence \& Kathy, 2018).

Healthcare professionals are expected to take part in mandatory continuing professional development programs to enhance their proficiency in practice and delivery of quality care to patients (Lawrence \& Kathy, 2018).

For the nursing profession in both developed and developing countries, Continuing Professional Development Programs have been identified as an important strategy towards improving basic professional skills (Chong, 2013). Carey \& Courtenay, (2007) similarly asserted that nurses' responsibilities at all levels of health care delivery are very essential because they give direct and individualized care to patients with diverse health conditions. These professional responsibilities require them to develop interest in life-long continuing professional activities. Similarly, the International Council of Nurses (ICN) Code of Ethics stressed that nurses carry personal responsibility and accountability for nursing practice, and for maintaining competence by continual learning (ICN, 2012).

Sequel the above, several countries of the world such as the United State of America (USA), United Kingdom (UK), Australia, China and some countries in sub-Saharan Africa have made continuing professional program compulsory for all health care professionals including nurses towards ensuring quality care, bridge the gap between theory and practice in addition to enhancing professional advancement. (Lucy et al., 2012; Chong et al., 2011).

In Nigeria, the Nursing and Midwifery Council of Nigeria (N\&MCN), introduced the Mandatory Continuing Professional Development Program in March 2010 with the aim of: promoting good leadership qualities managerial and organizational skills among nurses thereby enhancing preceptorship and mentorship as a tool for building a dynamic profession; to expose nurses to current development as well as new trends in health and nursing care; to sharpen the knowledge and skills of nurses on better ways of rendering qualitative, individualized, goaldirected nursing care using the process approach; to constantly bring to the fore health issues and conditions that constitute serious health challenges to the individuals, families and communities at large; seek to correct significant deficiencies and weaknesses that militate against qualitative nursing care delivery in health care institutions and at community level and to be a requirement for participation in council's activities and assignments as well as nerve (N\&MCN, 2012). 
In view of the above submission, all categories of nurses and Midwives are expected to attend minimum of five- day learning activities every three years during which they are required to achieve minimum of 6 points of the continuing education unit (CEU) equivalent to 60 contacthours as prerequisite for renewal of practicing license; three (3) units of these CEU must be obtained from N\&MCN organized MCPDP while the other 3 credit units can be obtained from conferences organized by International Confederation of Nurses (ICN), International Confederation of Midwives (ICM) or other conferences, workshops and seminars in Nursing specialties and sub specialties that are recognized by Nursing and Midwifery Council (N\&MCN, 2012).

Several studies have attempted to assess the level of knowledge and perception of Nurses about MCPDP (Nsemo et.al, 2013), the quality of MCPDP and its influence on healthcare providers' specific learning application and practice outcomes (Muliira et al., 2012). Few information has been documented regarding the usefulness of MCPDP training to nursing practice. Similarly, a dearth of information also remains about the level of satisfaction of nurses and midwives about MCPDP training in this study area. This study therefore explored nurses' perception about MCPDP training, usefulness of the MCPDP on nursing practices and level of satisfaction of nurses with the MCPDP in Osun State, Nigeria. Towards achieving the above objectives, this study employed Application Process Framework (APF) developed by Cividin and Ottoson (1997). The Application Process Framework (APF) model illustrates the complex process linking participation in Continuing Professional Education (CPE) with application of information learned to work-related settings. The APF model is consistent with transfer of training and adult learning theories (Cividin \& Ottoson, 1997). The model stipulates that application of learnt experience involves multiple factors, including predisposing, enabling, and reinforcing factors.

Predisposing factors are conceptualized as individual characteristics of participants; enabling and reinforcing factors are associated with forces external to the individual and represent both barriers and reinforcing factors. Enabling factors may include limited human and material resources, administrative bottleneck and protocols (Cividin \&Ottoson, 1997). Other factors includes financial constraints and restrictions on implementation of training experience as significant perceived barriers. Reinforcing factors represent positive or negative expectations and supports for post-training application. This includes lack of support from colleague for new innovations and resistance from agencies have been cited as significant barriers in continuing education. Factors identified above have also been identified to influence both participation in Continuing Professional Education and application of information learned (Furze \& Pearcey, 2001).

Applying the model above in this study was with a view to making appropriate recommendations from study findings towards advancement in nursing and midwifery practices, professional growth and provision of high quality patient care services.

\section{Aim of study}

This study explored nurses' perception about the Mandatory Continuing Professional Development Program, assessing nurses' satisfaction with the Continuing Professional Development Program in Nigeria. 


\section{MATERIALS AND METHOD}

\section{Study setting}

This study was conducted in Osun state, South-west Nigeria between June $15^{\text {th }}$ and $12^{\text {h }}$ August, 2019. Osun state extends through an area spanning approximately 12,820 square $\mathrm{km}$. Osun state is politically divided into three Senatorial districts with 30 Local Government Areas (LGAs) and an area office. The state is located within the interior of the cocoa belt of the Southwestern region of Nigeria. The 2006 National Population Census, Osun States has an estimated population of about 3,423,535 people consisting 1,740,619 males and 1,682,916 females. Osun state has 30 Local Government Areas (LGAs) and an area office which are distributed into the three Federal Senatorial districts namely: Osun West, Osun Central and Osun East Senatorial districts. The main ethnic groups in Osun state are Yorubas while sub-ethnic groups include Ife, Ijesha, Oyo and the Igbominas. The state also accommodates other ethnic groups from other parts of Nigeria such as the Ibos, Itsekiris, Ijaws, Hausas, Fulanis, Igalas and several other ethnic groups. The people of Osun state are mostly farmers, producing cash crops such as cocoa, and palm produce and food crops such as yam, maize, cassava, beans, plantain, banana and cocoyam. This is in addition to other skilled professionals having sources of income in the state.

\section{Study Design}

The study adopted sequential explanatory mixed methods design, using both quantitative and qualitative data collection methods. The quantitative aspect of the study was descriptive crosssectional design while the qualitative study employed in-depth interview (IDI).

\section{Study Population}

The study included nurses in Osun state

Inclusion criteria: Nurses who have attended the MCPDP training in Osun state

\section{Sample size determination}

The sample size for this study was estimated using the Cochran formula: $\mathrm{n}=\mathrm{Z} 2 \mathrm{pq} / \mathrm{d} 2$

Where $\mathrm{n}=$ desired sample size, $\mathrm{Z}=$ standard normal deviate at $95 \%$ confidence level (at $95 \%$ confidence level, $Z=1.96), p=$ maximum variability of the population at $50 \%$ i.e. $(0.5)$

$\mathrm{q}=1-\mathrm{p}, \mathrm{q}=1-0.5=0.5, \mathrm{~d}=$ degree of accuracy taken as 0.05

$\mathrm{n}=1.962 \times 0.5 \times 0.5$

$$
0.05^{2}
$$

$\mathrm{n}=384.16$ approximately 384 (minimum sample size). This was increased to 422 to give allowance for $10 \%$ attrition rate. A total of 422 were selected for the quantitative study, responses from 412 nurses were analyzed giving rise to $97.6 \%$ response rate. 


\section{Sampling technique}

Sampling for quantitative study: Multi-stage sampling technique was used for this study: Stage one involved selection of two senatorial districts from the three Senatorial districts in Osun State by simple random sampling technique (balloting); Stage two involved selection of two Local Government Areas from each selected senatorial district by simple random sampling technique (balloting); Stage three involved purposive selection of one Primary Health Care facility and one secondary and one Tertiary health facility (an additional secondary facility was considered where there was no tertiary health facility).Stage four involved selection of nurses at the selected health facilities by convenient sampling technique.

Sampling for qualitative study: Participants for the In-depth Interview were selected by snowballing sampling technique. Twenty participants participated in the in-depth interview.

\section{Instrument for data collection}

A semi structured self-developed questionnaire was used for the quantitative data collection. The questionnaire had the following sections: Section A contained eight items on sociodemographic characteristics of nurses. Section B is a 5-point Likert scale (1=disagree, $2=$ strongly disagree, $3=$ indifferent, $4=$ agree, $5=$ strongly agree) with ten items to explore the perception of nurses about MCPDP training. Section $\mathrm{C}$ is a 4-point Likert scale ( $1=$ very useful, $2=$ moderately useful, $3=$ useful, $4=$ not useful) with ten items which contain information on nurses' assessment of usefulness of MCPDP training on nursing practice. Section D is a 5point Likert scale (1=very satisfied, 2=satisfied, 3=indifferent, 4=dissatisfied, 5=very dissatisfied) with ten questions to assess nurses' level of satisfaction with MCPDP training in Osun State.

\section{Qualitative data collection}

Qualitative data was collected through In-depth Interview (IDI). An in depth interview Guide with sixteen open ended questions was used to explore participants' perception about MCPDP training in Osun state. Twenty nurses (both from the clinical and academic settings) who have attended MCPDP training in Osun state were interviewed. Responses of participants were recorded using a tape recorder. Hand written notes were also taken during the interview to supplement the audio recordings.

\section{Validity of research instruments}

Validity of instrument was ensured by subjecting the research instruments to face and content validity. The instruments were examined by experts in the field of Nursing Science, Public health, Demography and Social Statistics.

\section{Reliability of research instruments}

Reliability of the instrument was determined by the test re-test method. This involved pretesting of the instrument twice (within a period of two weeks interval) among participants of similar characteristics who are not within the study setting. Responses were analyzed. Internal consistency of the research instrument was determined by estimating Cronbach's alpha for the instrument which was 0.92 . 


\section{DATA ANALYSIS}

\section{Quantitative data analysis}

Quantitative data from this study was processed and analyzed using IBM Statistical SPSS version 25. Analysis was done at univariate, bivariate and multivariate levels: Univariate analysis was done using frequency and percentage distribution. Bivariate analysis was done to examine relationship between dependent variable and each of independent variables as well as the significance of the relationship. Cross tabulations and chi-square tests were used to determine relationship between dependent variable and each of independent variables as well as selected background characteristics of respondents. P-value less than 0.05 was considered significant. Multivariate analysis was done to predict simultaneous effects of independent variables on dependent variable using binary logistic regression.

\section{Qualitative data analysis}

Responses from the in-depth interview were edited, while relevant details were extracted from field notes. Similarities and differences in views regarding Nurses' Assessment of the Usefulness of Mandatory Continuing Professional Development Program Training were identified, analyzed and reported.

\section{Ethical permission}

Ethical permission was obtained from Osun State Ministry of Health. Verbal consent was also sought from nurses before data collection. Information obtained was kept confidential and used for research purposes only.

\section{Results}

Findings showed that the mean age for the nurses was 40 years, $136(33.0 \%)$ nurses were aged $30-39$ years old, $41(10.0 \%)$ of the nurses were between $20-29$ years old while only $5(1.2 \%)$ were above 60 years old, $351(85.2 \%)$ of the nurses were female while $61(14.8 \%)$ were males (Table 1). Findings also revealed that that 251 (60.9\%) nurses had Bachelor degree, $42(10.2 \%)$ had master degree, only $4(1 \%)$ had $\mathrm{PhD}$ degree, 230 (55.8\%) had below10 years working experience, $182(44.2 \%)$ had 10-19 years working experience, $56(13.6 \%)$ had worked for 30 years and above. Three hundred and thirty four nurses $(81.1 \%)$ practice as nurse clinician, 54 $(13.1 \%)$ were nurse educators while $24(5.8 \%)$ were nurse administrators (Table 2).

\section{Nurses' Perception about MCPDP}

\section{Perceived the MCPDP as platform for personal and professional development}

Three hundred nurses $(72.8 \%$ ) had a positive perception about the Mandatory Continuing Professional Development Program (MCPDP) training (Figure1).

Similarly, responses from the in-depth interview revealed that nurses generally perceived the MCPDP training as a platform for personal and professional development and that training should remain compulsory for all nurses in view of its importance in intellectual development. 
In supporting this general opinion, a nurse clinician with Registered nurse certificate responded that:

“... the MCPDP training is a welcome development because the training had offered me the opportunity to remember basic rudiments of the health care and the nursing profession"

\section{(a nurse clinician with registered nurse certificate)}

This opinion was supported by another nurse clinician who reported that the MCPDP training has been very useful especially in the area of career and skill development. Below is an excerpt from her responses:

“... the MCPDP is an important training that must be encouraged among nurses as it is done among other health professionals. The training should be organized more frequently so that enough opportunities would be available for nurses"

(a nurse clinician with registered nurse, registered midwife certificate)

\section{Perceived that the MCPDP enhances intellectual and professional competence}

In responding to the above sub-theme, a nurse educator opined that:

“...the MCPDP training has really improved my understanding of some nursing concepts. It has also reminded me of some basic nursing teachings. I know that nursing profession has moved forward now and the MCPDP training has bridged the gap between our nursing training and the new trend"

\section{( $a$ nurse educator with bachelor degree)}

\section{Perceived the MCPDP should be remain mandatory}

Participants were asked to express their opinion whether the MCPDP training should be made optional, participants generally opined that the MCPDP should remain compulsory and be attached to practicing license renewal. Below are some responses:

"...In my own opinion, the MCPDP training should continue to be compulsory and be attached

to certain conditions such as renewal of license, otherwise people will not participate in the training if it's optional".

\section{(a nurse clinician with degree certificate)}

A divergent view was however expressed by another participant who opined that the MCPDP training should not be made compulsory especially for people with busy work schedules. Below is an excerpt her opinion: 
“.. in as much as the MCPDP training is a welcome development, it should not be made compulsory because there are no sufficient time for all nurses to attend especially nurse in very busy schedule"

(a nurse clinician with registered midwife certificate)

\section{Nurses' assessment of the usefulness of MCPDP training on nursing practices}

Findings also revealed that $273(66.3 \%)$ nurses assessed the MCPDP training as being very useful while $129(31.3 \%)$ and $10(2.4 \%)$ assessed the training as moderately useful and useful respectively (Figure 2).

\section{Perceived the MCPDP as useful for skill and intellectual development}

Participants opined that the scope of the training program should be widened to further incorporate practical demonstrations of nursing skills and procedures. In their responses, a nurse clinician who has been in private practice for over 10 years responded that:

“...the MCPDP is a welcome development, the training has brought back to memory key nursing

teaching and skills. There could not have been any other substitute to the MCPDP training. More areas of nursing practice should be incorporated into the MCPDP curriculum especially practical demonstrations of current clinical procedures".

\section{(a nurse clinician with registered nurse certificate)}

To further support the above response, another nurse clinician responded that:

“...the MCPDP has been obviously useful in many areas, the training has improved my

knowledge about current nursing issues which are basic to the nursing profession. The training has taught me better ways to care for my patients, and I am sure my clinical nursing practice will improve tremendously from now".

( $a$ nurse clinician with registered nurse, registered midwife certificate)

A nurse educator also supported the above responses on the usefulness of the MCPDP training:

“... the MCPDP training has significantly broadened my knowledge in many areas, am sure

many of our colleagues, nursing students, nursing interns will benefit from the scheme since its introduction. The curriculum should be further expanded to include emerging and recent clinical procedures"

To further support the above responses on the usefulness of the MCPDP training, a nurse administrator opined that: 
“... the MCPDP training has been very useful to me personally and has also improved my

leadership skills. I want to strongly recommend that more management issues should be included into the module in the future".

\section{Nurses' satisfaction with MCPDP training}

In addition, 235 (57.0\%) nurses were very satisfied with the MCPDP training, 171 (41.5\%) nurses were satisfied while $6(1.5 \%)$ nurses were indifferent with the MCPDP training in Nigeria (Figure 3).

\section{Satisfied with the MCPDP training}

Participants were generally satisfied with previous sessions of the MCPDP training. Responding on the quality/ content of training, a nurse educator with master degree expressed some satisfaction about the consistency of selected topics and training theme:

"... I observed a good synergy between training topics and the broad theme during most $M C P D P$

training sessions that I have personally attended. I want to say that I am satisfied so far with the quality of training sessions though more is still needed to be done towards expanding the scope of training topics and practical demonstrations of clinical nursing skill“"

\section{(a nurse educator with master degree)}

The above opinion was similar to the submission of a nurse educator with a $\mathrm{PhD}$ certificate who responded that:

“...the MCPDP training has be very satisfactory though more attention should be given to

conference materials especially the quality of visual appliances and power point presentations and other conference materials. Future MCPDP training should involve professionals from other fields to broaden the scope of the MCPD training”.

\section{(a nurse educator with a PhD certificate)}

\section{The MCPDP offers quality, competent training and resources}

Speaking on his opinion about competence and quality of facilitators/ trainers, training facilities, a nurse educator responded that"

“... so far, resource persons for most MCPDP training have demonstrated satisfactory

competence and professionalism during MCPD sessions. I would further suggest inclusion of more experts who may not necessarily be nurse practitioner to undertake certain specialized sessions like contraception/family planning, HIV/AIDS, and so on in future MCPDP training"

\section{(a nurse educator with PhD degree)}


Similarly, in her view regarding organization of the training sessions and time management during MCPDP training session, a nurse administrator opined that:

“...most training sessions are comprehensive enough, though more allowances need be considered for feedback, clarifications, questions and reactions from participants laudience. This is to ensure balance in future MCPDP training”

(a nurse administrator with bachelor degree)

A nurse clinician similarly responded that:

“...the present Osun state MCPDP committee members have demonstrated maturity and good

understanding of the assignment given to them. This is reflected in their handling of issues and challenges, information dissemination and public relations. This is commendable, though this could be improved upon"

\section{(a nurse clinician with diploma certificate)}

The above response was similar to the comment made by another nurse clinician who responded that:

“... the present Osun MCPP committee members are approachable, patient and always ready to

help out. They respond promptly to clarification, questions and they give helping hands whenever needed"

(a nurse clinician with diploma certificate)

\section{Factors influencing nurses' perception about MCPDP}

Analysis at the bivariate level revealed significant association between perception about the MCPDP training and nurses' age $\left(\chi^{2}=23.03, \mathrm{df}=4, \mathrm{p}=0.01\right)$, years of working experience $\left(\chi^{2}=11.96, \mathrm{df}=3, \mathrm{p}=0.01\right)($ Table 3$)$.

Regression analysis further revealed that nurses' years of working experience significantly influenced their perception about the MCPDP program $(\mathrm{OR}=0.24, \mathrm{CI}=0.10-0.62, \mathrm{p}=0.003)$. The odds that nurses with 10-19 years working experience would have positive perception about the MCPDP training was 0.24 less than the odds for nurses with less than 10 years working experience (Table 4).

\section{DISCUSSION OF FINDINGS}

Findings showed that about the majority of the nurses had positive perception about the Mandatory Continuing Professional Development Program (MCPDP) training while only a third had negative perception about the training. Similarly, participants at the in-depth interview generally perceived that the MCPDP training is a platform for personal and 
professional development and that training should remain compulsory for all nurses in view of its importance in intellectual development.

The above finding is essential for the future participation and success of the MCPDP for nurses. Positive perception about MCPDP observed in this study corroborates the submission of Nolan, Owens \& Nolan (2005) who asserted that effective continuing education has been linked with raised staff morale, increased motivation, staff retention and development of leadership skills. Nsemo et al. (2013) similarly observed that nurses in southern Nigeria perceived that MCPDP training is highly valuable for nursing practices. These however contrast findings from a similar study in south-eastern part of Nigeria by Ihudiebube-Splendor et al. (2017) who observed that the majority of nurses had poor perception about MCPDP training.

Findings also revealed that nurses' age and years of working experience significantly influenced their perception about the MCPDP training at the bivariate level of analysis, though years of working experience remained a significant factor that significantly influenced their perception about the MCPDP training at the multivariate level of analysis. This finding is consistent with the submission of Osei et al. (2019) who identified personal factors, such as motivation, age, and years of work experience, as factors that could influence the likelihood of change in perception and professional practice as a result of continuing professional education. Brekelmans, Poell \& Wijk (2013) however identified Continuing Professional education registration system, opportunity for in-service learning, identification with the nursing profession, attractiveness to the nursing profession as factors that influence nurses' participation in Continuing Professional Development Programs. Chong et al. (2014) similarly observed that nurses' level of education and other demographic characteristics like age, years of working experience have significant influence on participation in MCPDP activities. Nsemo et al. (2013) in their study concluded that the MCPDP training is more relevant for nurse clinicians than nurse educators.

Furthermore, a quarter of the nurses assessed the MCPDP training as being very useful, a third of the nurses assessed the MCPDP training as moderately useful while very few assessed the training as useful. This finding is consistent with responses from the in-depth interview in which participants opined that the MCPDP training has been very useful to participants since its introduction. Participants further retorted that the scope of the training program should be widened to further broaden and incorporate practical demonstrations of nursing skills and procedures. This submission is supported by the submission of Nolan, Owens \& Nolan (2005) who asserted that nurses' roles and skills can be enhanced through continuing professional development which is also considered to be a key factor in nursing practices. Adamu et al. (2015) in their study in northern Nigeria and Giri et al. (2012) similarly asserted that continuing professional development training is essential towards successful health care delivery.

Finding also revealed that majority of the of the nurses were very satisfied with the MCPDP

A significant proportion of the nurses were satisfied while only a few were indifferent with the MCPDP training. Responses from the in-depth interview also showed that participants were generally satisfied with previous sessions of the MCPDP training; an indication that there was high level of satisfaction among nurses about the MCPDP training in Osun state, Nigeria. This 
development is expected to positively influence the quality of nursing practices in this study area. This submission is consistent with the assertion of Nolan, Owens and Nolan (2005) who concluded in their study that improvement in service delivery is easier to implement when the practitioners are highly motivated and the environmental variables are favourable for learning, for skill acquisition and improvement in knowledge. A study conducted by Chong et al. (2014) concluded that nurses in Malaysia appreciate the importance of continuing professional training and are highly motivated about MCPDP training.

Responses from the in-depth interview further showed that nurses generally opined that more attention should be given to the welfare of MCPDP training participants during the 5-day training and that MCPDP training should involve more practical demonstrations of basic nursing practices.

\section{CONCLUSION}

Majority of nurses studied had a positive perception about the Mandatory Continuing Professional Development Program. Nurses generally assessed the MCPDP training as being useful and are similarly satisfied with the MCPDP. Nurses' years of working experience significantly influenced their perception about the MCPDP program. Advocacy should focus on improving the quality of nurses' years of working experience.

\section{Implication of Findings to Nursing Practices}

Mandatory Continuing Professional Development Program (MCPDP) for nurses is an indispensable platform for lifelong learning, aimed at equipping the nurses' expertise and improving health outcomes by systematically improving and widening knowledge, understanding, skills and the development of personal qualities necessary for the execution of nursing duties, including the acquisition of new roles and responsibilities for the utmost advancement of the nursing profession. Advocacy should focus on ensuring that nurses have quality years of working experience and effective Continuous Professional Development training for nurses at all levels.

\section{Ethical Permission}

Ethical permission was obtained from the Ethics and Research Committee, Ministry of Health, Osun state, Nigeria

\section{Acknowledgement}

Authors wish to acknowledge the Mandatory Continuing Professional Development program Committee, Osun state, Nigeria for their technical and logistical support in the course of conducting this study.

Authors' contribution: Adebukunola Olajumoke Afolabi, Monisola Yetunde J. Omishakin and and Tolulope Margaret Agboire undertook original conceptualization, design validation of research instrument and data analysis, Phebe Olufunke Abioye and Mary Olufunke AkinAyankunle were responsible for procuring ethical permission and research protocol and supervision of data collection for this study, Adebayo Lukman Ademola, Margaret Omobonike 
Ogundeji undertook the qualitative data collection and analysis while Samuel Olumide Faniran and Adeola Omobola Adegoke undertook the final manuscript writing and editing.

\section{REFERENCES}

Adamu, A., Adeleke, I.T., Aliyu, D. \& Mahmud, T. (2015). Perspectives of continuing formal education among nurses in selected secondary health care facilities in northern Nigeria. American journal of health research; 3 (1), 68-73. Doi: 10.11648/j.ajhr.s.2015030101.20

Banning, M. \& Stafford, M. (2008). A hermeneutic phenomenological study of community nurses' CPD. Clinical Review, 13(4), 178-182.

Banova, B. (2014). The impact of technology on healthcare. American institute of medical sciences and education. https://www.aimseducation.edu/blog/the-impact-of-technologyon-healthcare/

Brekelmans, G., Poell, R.F. \& Wijk, K. (2013). Factors influencing continuing professional development: A Delphi study among nursing experts. European journal of training and development; 37(3). Doi: 10.1108/03090591311312769

Carey, N. \& Courtenay, M. (2007). A review of the activity and effects of nurse-led care in diabetes. J Clin Nurs 16: 296-304. Retrieved from https://www.ncbi.nlm.nih.gov/pub med/ 17931323

Chong, M.C., Karen F.K. \& Simon C.M. \& Khatijah, L.A. (2014). Current Continuing Professional Education Practice among Malaysian Nurses. Nursing Research and Practice. https://www.hindawi.com/journals/nrp/2014/126748/

Cividin, T.M. \& Ottoson, J.M. (1997). Linking reasons for continuing professional educationparticipation with post program application. Journal of Continuing Education in the Health Professions; 17:46-55.

Furze, G. \& Pearcey, P. (2001). Continuing education in nursing: a review of the literature. Journal of advanced nursing; 29(2); 355-366. https://doi.org/10.1046/j.13652648.1999.00896.x

Giri, K., Frankel, N., Tulenko, K., Puckett, A., Bailey, R. \& Ross, H. (2012). Keeping up to date: continuing professional development for health workers in developing countries. Capacity plus technical brief; 6 . https//www.who.int $>$ resources $>$ ca...

Ihudiebube-Splendor, C.N., Odikpo, L.C., Ogwu, J. O., Chinweuba, A.U. \& Osuala, E. O. (2017). Mandatory continuing education for professionals development program: perception of nurses in university of Nigeria teaching hospital, Ituku-Ozalla, Enugu state, Nigeria. International journal of science and research; 6 (5).

Doi:10.21275/ART20173403

International Council of Nurses, (2012). The ICN code of ethics for nurses. www.icn.ch

Lawrence, T. S. \& Kathy, B. C. (2018). Global perspective on continuing professional development. The Asia pacific scholar, 3(2) 1-5. https://doi.org/10.29060/TAPS.20183-2/GP1074

Lucy, S., Johnson, V. \& Long, P. D. (2012). Continuing Professional Development: the Missing link. Manual Therapy Journal. 17, 89-91. http://doi.org/101016

Muliira, J.K., Etyang, C., Muliira, R. \& Kizza, I.B. (2012). Nurses' orientation toward lifelong learning: A case study of Uganda's national hospital. The journal of continuing education in nursing; 43(2):90-6. Doi: 10.3928/00220124-20111003-03 
Nolan, M., Owens, R. \& Nolan, J. (2005). Continuing professional education: Identifying the characteristics of an effective system. Journal of Advanced Nursing.2005, 21, 551-560

Nsemo, A.D., John, M.E., Etifit, R.E., Mgbekem, M.A. \& Oyira, E.J. (2013). Clinical nurses' perception of continuing professional education as a tool for quality service delivery in public hospitals Calabar, Cross River State, Nigeria. Nurse Education in Practice, 13(328)334. https://www.researchgate.net/publication/236690633

Nursing and Midwifery Council of Nigeria (N\&MCN). (2012). Nursing and Midwifery Council code of professional conduct. https://www.nmcn.gov.ng>codec2

Osei, S.A., Boahemaa, F.A., Peprah, W.K., Marfo-Kusi, A.A. \& Pinamang, B.N. (2019). Continuous professional development on job performance of registered nurses in Ghana. Abstract proceedings international scholar conference; 7(1):116-128. https://jurnal.unai.edu>article 
APPENDIX

Table 1: Socio-Demographic Characteristics of Nurses

$\mathrm{n}=\mathbf{4 1 2}$

\begin{tabular}{lcc}
\hline Variable & Frequency & \% \\
\hline Age group (years) mean $=\mathbf{4 0} \mathbf{3}$ SD & & \\
$20-29$ & 41 & 10.0 \\
$30-39$ & 136 & 33.0 \\
$40-49$ & 119 & 28.9 \\
$50-59$ & 111 & 26.9 \\
$* 60$ and above & 5 & 1.2 \\
Sex & 61 & \\
Male & 351 & 14.8 \\
Female & & 85.2 \\
Marital status & 390 & 94.7 \\
Married & 10 & 2.4 \\
Single & 6 & 1.5 \\
Divorced & 6 & 1.5 \\
Widow & & \\
Religion & 343 & 83.3 \\
Christianity & 66 & 0.7 \\
Islam & 3 & \\
Traditionalists & & \\
\end{tabular}

* This study included retired nurses who were 60 years and above.

Table 1 shows that 343 (83.3\%) nurses were Christian, 390 (94.7\%) were married.

Table 2: Professional Characteristics of Nurses $n=412$

\begin{tabular}{lcr}
\hline Variable & Frequency & \% \\
\hline Highest level of education & 115 & 27.9 \\
Diploma & 251 & 60.9 \\
Bachelor degree & 42 & 10.2 \\
Master degree & 4 & 1.0 \\
PhD & & \\
Professional Qualification & 195 & 47.3 \\
Registered Midwife & 43 & 14.6 \\
Registered Public Health Nurse & 12 & 10.4 \\
Registered Peri-operative Nurse & 47 & 2.9 \\
Registered Mental Health Nurse & & 11.4 \\
Registered Nurse Educator &
\end{tabular}


Registered Nurse Administrator

Years of working experience

$\leq 10$ years

$10-19$

230

182

106

56

30 and Above

Area of Practice

Nurse Clinician

Nurse Educator

Nurse Administrator

**Modules previously attended

Medical Surgical Nursing

Midwifery

Community/Public Health Nursing

Psychiatric Nursing

Contraceptive update

Adolescent Health

Psychosocial support

*Others Professional Qualifications include Registered Orthopaedic nurse, Nurse

Anaesthetist,

Ophthalmic Nurse, Occupational Health, Nurse, ENT Nurse, Intensive Care Nurse, Accident emergency Nurse

**More than one modules were selected

Table 2 shows that $230(55.8 \%)$ of the nurses previously attended Medical surgical training module, $74(18 \%)$ previously attended midwifery module while $52(12.6 \%)$ had previously attended Psychosocial support module.

Table 3: Factors Influencing Nurses' Perception about the MCPDP Training

$n=412$

\begin{tabular}{|c|c|c|c|c|c|c|}
\hline \multirow[b]{2}{*}{ Variables } & \multicolumn{2}{|c|}{$\begin{array}{l}\text { Nurses' Perception } \\
\end{array}$} & \multirow[b]{2}{*}{$\begin{array}{r}\text { Total } \\
\text { n }(\%)\end{array}$} & \multirow{2}{*}{\multicolumn{2}{|c|}{ Statistic }} & \multirow[b]{2}{*}{$\mathrm{p}$} \\
\hline & $\begin{array}{l}\text { Negative } \\
\mathbf{n}(\%)\end{array}$ & $\begin{array}{l}\text { Positive } \\
\text { n }(\%)\end{array}$ & & & & \\
\hline Age group (years) & & & & & 23.03 & 4 \\
\hline \multicolumn{7}{|l|}{0.01} \\
\hline $20-29$ & $10(24.4)$ & $31(75.6)$ & & 100.0 & & \\
\hline $30-39$ & $56(41.2)$ & $80(58.8)$ & & 100.0 & & \\
\hline $40-49$ & $28(23.5)$ & $91(76.5)$ & & 100.0 & & \\
\hline $50-59$ & $18(16.2)$ & $93(83.8)$ & 11 & 100.0 & & \\
\hline
\end{tabular}


African Journal of Health, Nursing and Midwifery

ISSN: 2689-9418

Volume 4, Issue 6, 2021 (pp. 119-138)

www.abjournals.org

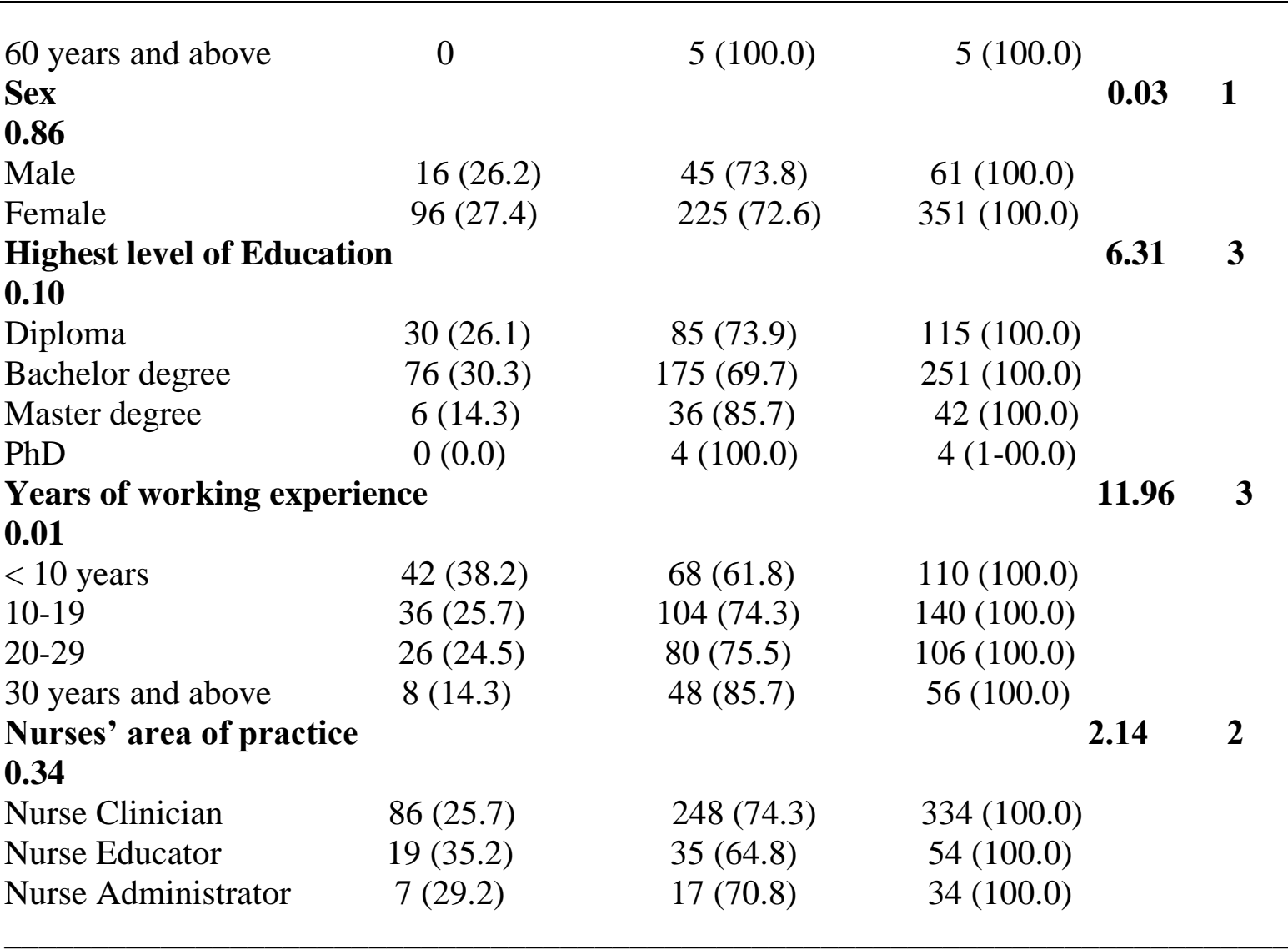

Table 3 shows that there was no significant relationship between perception about MCPDP training and nurses' sex $(p=0.86)$, area of practice $(p=0.34)$.

Table 4: Regression Analysis of Factors Influencing Nurses' Perception about the MCPDP Training

Age group (years)

Less than 30

$\mathrm{RC}-1$

30-59

$\begin{array}{lll}0.99 & 0.001 & 0.00-0.001 \\ 0.99 & 0.001 & 0.00-0.001\end{array}$

60 and above

$P$ value Odd Ratio $(\mathrm{OR}) \quad$ Confidence Interval $(\mathrm{CI})$

Sex

Male

Female

$\mathrm{RC} \quad 1$

Highest level of education

Diploma

Bachelor degree

Master degree

$\mathrm{PhD}$

0.73

0.89

$0.45-1.72$

Area of practice

Nurse clinician

Nurse educator

$\mathrm{RC} \quad 1$

$\begin{array}{lll}0.99 & 0.001 & 0.00-0.001 \\ 0.99 & 0.001 & 0.00-0.001 \\ 0.99 & 0.001 & 0.00-0.001\end{array}$

$\mathrm{RC} \quad 1$

$\begin{array}{lll}0.35 & 1.65 & 0.60-4.30\end{array}$




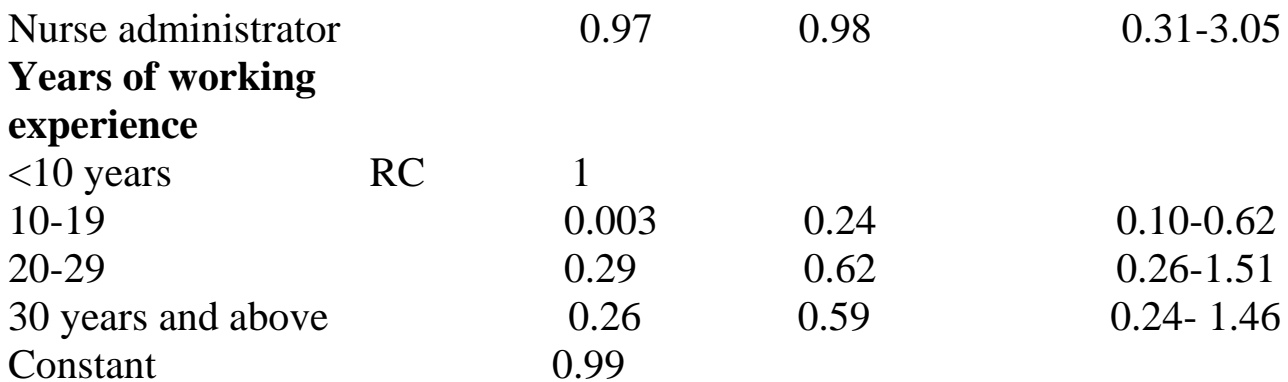

Table 4 shows that nurses' age, sex, highest level of education, area of practice had no significant influence on nurses' perception about MCPDP program.

Table 5: Qualitative responses on Nurses' Assessment of MCPDP Training

\begin{tabular}{|l|l|l|}
\hline Main theme & Themes & Sub-themes \\
\hline $\begin{array}{l}\text { Perception about } \\
\text { MCPDP }\end{array}$ & $\begin{array}{l}\text { Perception about } \\
\text { usefulness }\end{array}$ & $\begin{array}{l}\text { Perceived the MCPDP as platform for } \\
\text { personal and professional development } \\
\text { and should remain compulsory }\end{array}$ \\
\hline & $\begin{array}{l}\text { Perceived the MCPDP enhances } \\
\text { intellectual and professional competence }\end{array}$ \\
\hline & $\begin{array}{l}\text { Perceived the MCPDP should be remain } \\
\text { mandatory }\end{array}$ \\
\hline & $\begin{array}{l}\text { Perceived the MCPDP as useful for skill } \\
\text { and intellectual development }\end{array}$ \\
\hline & Satisfaction with the & Satisfied with the MCPDP training \\
\hline & & $\begin{array}{l}\text { The MCPDP offers quality, competent } \\
\text { training and resources }\end{array}$ \\
\hline
\end{tabular}




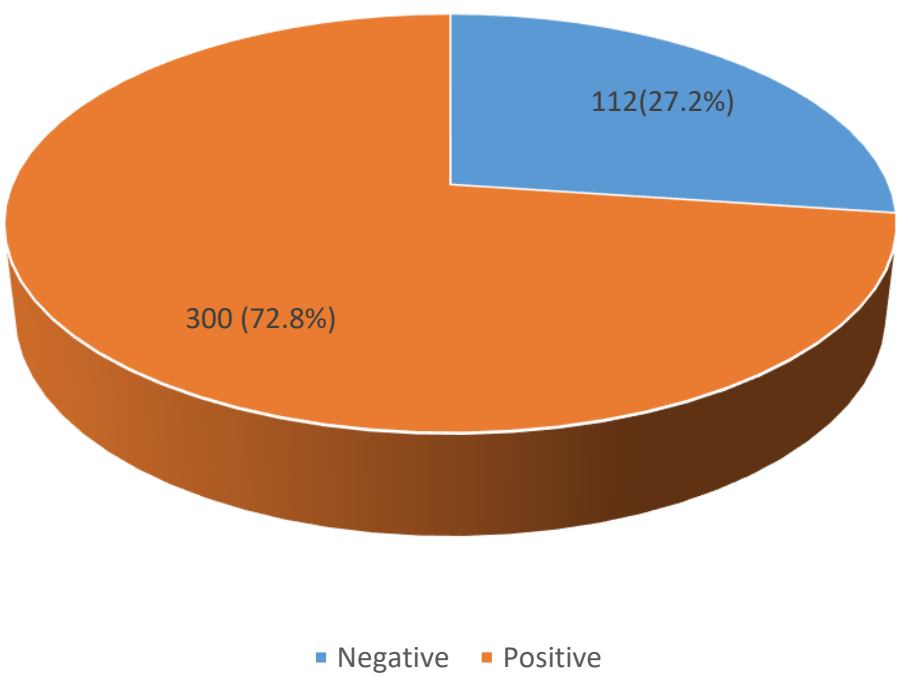

Figure 1: Nurses' perception about the Mandatory Continuing Professional Development Program (MCPDP)

Figure 1 shows that 112 (27.2\%) nurses had negative perception about the MCPDP training

$129(31.3 \%)$

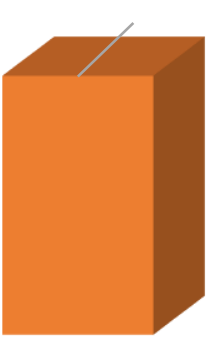

Useful

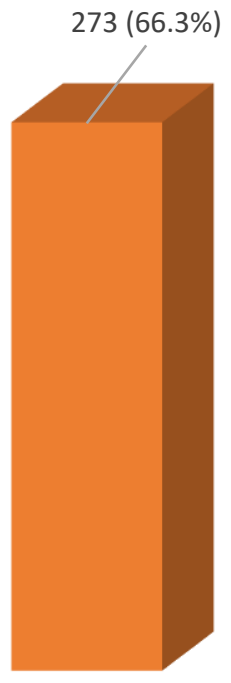

Very Useful

Figure 2: Nurses' assessment of the usefulness of MCPDP training on nursing practices

Figure 2 shows that $10(2.4 \%)$ nurses assessed the MCPDP training as useful 
African Journal of Health, Nursing and Midwifery

ISSN: 2689-9418

Volume 4, Issue 6, 2021 (pp. 119-138)

www.abjournals.org

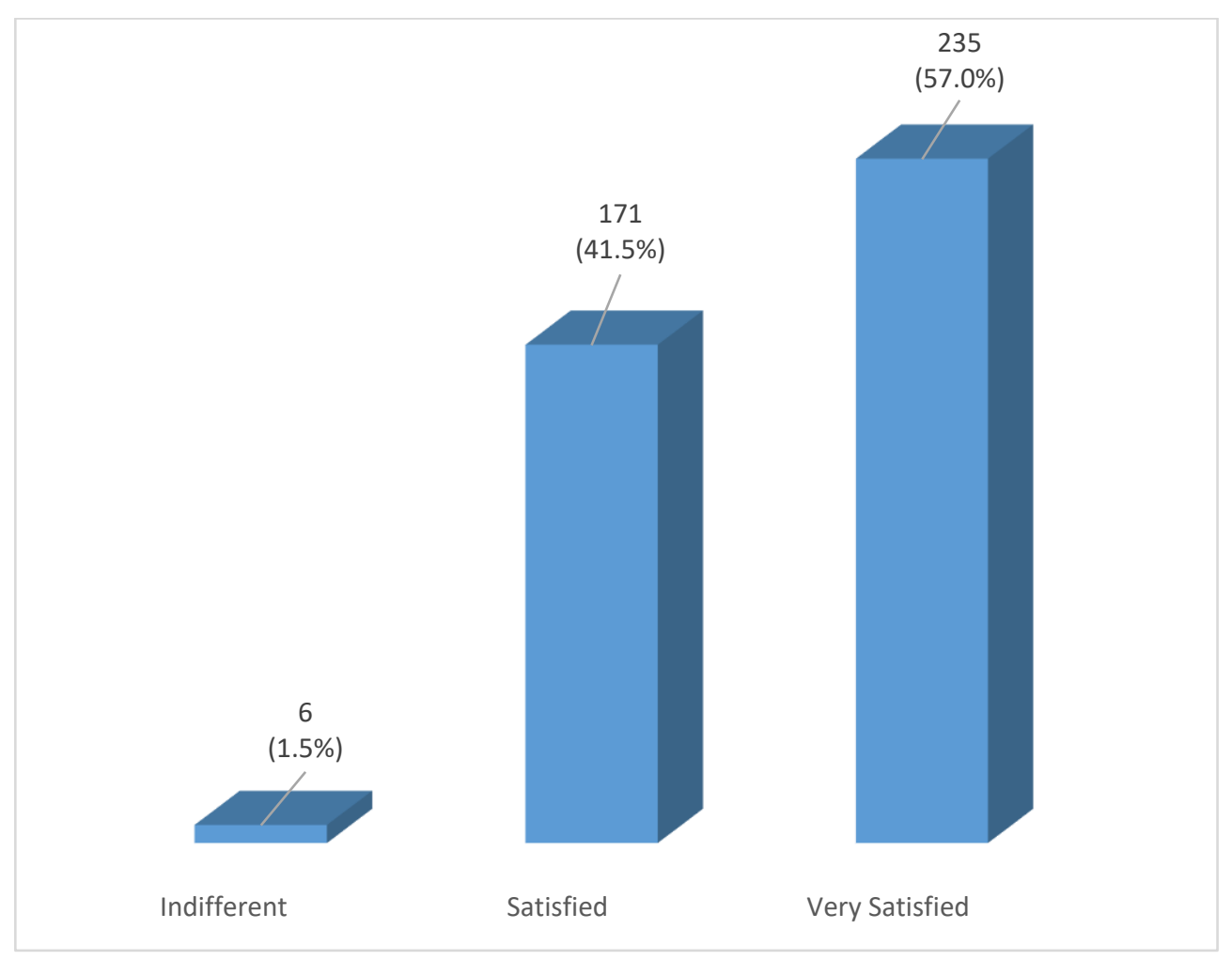

Figure 3: Nurses' satisfaction with MCPDP training

Figure 3 shows that $6(1.5 \%)$ nurses were indifferent with the MCPDP training 